\title{
PARÂMETROS FÍSICO-QUÍMICOS E MICROBIOLÓGICOS DO LEITE EM FUNÇÃO DA SAZONALIDADE
}

\author{
Microbiological and physicochemical characterization \\ of milk according to the seasons
}

\author{
Rafael Fagnani ${ }^{I^{*}}$, Ana Paula Pavão Battaglini ${ }^{2}$, Vanerli Beloti ${ }^{2}$, Josiane Schuck ${ }^{1}$, \\ Felipe Nael Seixas ${ }^{2}$, Paulo Eduardo Carraro ${ }^{3}$
}

\begin{abstract}
RESUMO
As estações do ano têm grande influência na produção leiteira, principalmente quando os animais lactentes ficam expostos às suas variações climáticas. No Brasil, essa situação é recorrente, sendo necessários maiores esclarecimentos a fim de amenizar os prejuízos decorrentes de oscilações em componentes do leite. O objetivo foi avaliar como a sazonalidade influencia os componentes físico-químicos e a qualidade microbiológica do leite cru da região de Ivaiporã - PR. Assim, o leite produzido em propriedades do norte do Paraná foi analisado durante o decorrer de 24 meses. As amostras foram quantificadas quanto à porcentagem de lactose, proteínas, gordura, sólidos totais, contagem de bactérias totais e contagem de células somáticas. O índice pluviométrico regional e a temperatura média registrada em cada estação foram analisados para a determinação de Índice de Conforto Térmico e avaliação do estresse térmico sofrido pelos animais. Este estudo concluiu que a sazonalidade tem influência nas características microbiológicas e físico-químicas do leite na região de Ivaiporã, com maiores porcentagens de sólidos no outono e pior qualidade microbiológica na primavera.
\end{abstract}

Palavras-chave: estações do ano; gordura; sólidos; proteína; CBT; CCS.

1 Universidade Norte do Paraná (UNOPAR), Programa de Mestrado em Ciência e Tecnologia de Leite e Derivados, Rua Marselha, 591, 86041-100, Londrina, PR, Brasil. E-mail: rafaelfagnani@hotmail.com

2 Universidade Estadual de Londrina (UEL), Centro de Ciências Agrárias, Departamento de Medicina Veterinária Preventiva, Laboratório de Inspeção de Produtos de Origem Animal (LIPOA), Londrina, PR, Brasil.

3 Universidade Estadual do Norte do Paraná (UENP), Centro de Ciências Agrárias, Setor de Veterinária Produção Animal, Campus Luiz Meneghel, Bandeirantes, PR, Brasil.

* Autor para correspondência. 


\begin{abstract}
The seasons have a major influence on milk production, especially when animals are exposed to climatic variations. This situation is very common in Brazil and further investigation is needed to understand the losses caused by oscillations in milk constituents. The aim was to evaluate how seasonality can affect the physicochemical and microbiological quality of raw milk in Ivaiporã region, state of Paraná, Brazil. In this research, the milk from properties in northern Paraná was evaluated during 24 months for lactose, protein, fat, total solids, total bacteria count and somatic cell count. The regional rainfall and average temperature recorded at each station were analyzed for determination of Thermal Comfort Index and evaluation of heat stress. This study concluded that seasonality have influence on microbiological and physicochemical quality of milk in Ivaiporã region, with higher percentages of solids in the fall and inferior microbiological quality in the spring.
\end{abstract}

Keywords: seasons; fat; solids, protein, TBC; SCC.

\section{INTRODUÇÃO}

A produção leiteira dentro de uma região pode ser bastante heterogênea. Essa realidade pode ser vista no Paraná, onde apenas três bacias leiteiras são responsáveis por aproximadamente $60 \%$ da produção do estado (IBGE, 2013).

As demais regiões paranaenses possuem características opostas aos polos leiteiros, mas são responsáveis pelos outros $40 \%$ da produção. Nessas regiões a atividade leiteira é frequente, presente em $70 \%$ das propriedades (BAZOTTI et al., 2012). A microrregião de Ivaiporã segue essas características, sendo composta por propriedades familiares com ordenha manual e bezerro ao pé, com base alimentar a pasto e fornecimento esporádico de cana de açúcar no período de escassez de alimentos (BATTAGLINI et al., 2013a).

As indústrias laticinistas locais costumam incentivar a produção dos seus associados através do pagamento do leite por qualidade (BATTAGLINI et al., 2013b). Esse tipo de bonificação é baseado nas características físico-químicas e microbiológicas do leite, sendo que flutuações nesses parâmetros podem ocorrer ao longo do ano (FERNANDES et al., 2013).
A sazonalidade pode influenciar a composição do leite, e por sua vez, o rendimento de produtos lácteos. O efeito da sazonalidade é resultado principal da variação pluviosidadetemperatura entre o período de inverno e o período de verão (SOUZA et al., 2010).

A partir de estudos que caracterizam a produção regional, as indústrias e os produtores podem prever os fatores sazonais que afetam a qualidade do leite, possibilitando que medidas preventivas sejam implantadas, otimizando e racionalizando a produção e/ou o beneficiamento de produtos lácteos.

O objetivo foi avaliar como a sazonalidade influencia os componentes físicoquímicos e a qualidade microbiológica do leite cru na microrregião de Ivaiporã-PR, relacionando as possíveis oscilações com as respectivas causas mais prováveis.

\section{MATERIAL E MÉTODOS}

Durante 24 meses foram coletadas 1263 amostras de leite cru assim distribuídas: 220 amostras no outono, 228 amostras no inverno, 661 amostras na primavera e 154 amostras no verão. A coleta foi feita diretamente de latões e resfriadores de imersão ou expansão em uma linha de produtores da microrregião 
de Ivaiporã, na região norte-central do estado do Paraná. A coleta foi aleatória através de sorteio randômico entre as propriedades cadastradas no laticínio. O número de propriedades cadastradas variou de 210 a 805 durante o período do estudo. As propriedades sorteadas não foram excluídas dos próximos sorteios, e havia possibilidade da mesma ser sorteada novamente. De todas as propriedades utilizadas, 302 foram caracterizadas através da aplicação de questionário e observação. As condições climáticas durante o período de coleta foram obtidas através do Instituto Nacional de Meteorologia (INMET, 2011).

As amostras foram homogeneizadas com auxílio de uma concha flambada e aproximadamente $200 \mathrm{ml}$ foram coletados, divididos igualmente em frascos de polietileno, sob refrigeração em caixas isotérmicas com gelo reciclável.

Os frascos de polietileno continham bronopol para a determinação da composição centesimal pela metodologia de infravermelho (INTERNACIONAL IDF STANDARD $141 \mathrm{C}, 2000)$ e azidiol para a contagem total de bactérias por citometria de fluxo (INTERNACIONAL IDF STANDARD 196, 2004). Os frascos foram encaminhados ao laboratório da Associação dos Produtores e Criadores de Bovinos da Raça Holandesa (APCBRH), Curitiba-PR, onde foram mensuradas a porcentagem de gordura, proteína, lactose, sólidos totais (ST), contagem de células somáticas (CCS) e contagem bacteriana total $(\mathrm{CBT})$.

O delineamento experimental foi inteiramente casualizado e as variáveis analisadas foram porcentagem de gordura, de proteína, de lactose, de sólidos totais (ST), contagem de células somáticas (CCS) e contagem bacteriana total (CBT). As variáveis que não tiveram distribuição normal pelo teste de Lilliefors (CCS e CBT) foram normalizadas por transformação logarítmica. Os dados foram submetidos à análise de variância ponderando o efeito da sazonalidade (outono, primavera, inverno e verão) sobre os componentes do leite. Fatores com $\mathrm{p}<0,05$ foram posteriormente analisados pelo teste de Tukey a 5\% de probabilidade. Para todas as análises foi utilizado o programa Statistica 7.0.

\section{RESULTADOS E DISCUSSÃO}

As 302 propriedades localizadas na região do estudo tinham predomínio de produtores de pequeno porte com média de 18,64 animais por propriedade. $\mathrm{O}$ número médio de animais em lactação foi de 7,46 e a produtividade média de leite diária foi de 6,04 litros por animal.

Animais de raça não definida e Girolanda foram os mais frequentes nas propriedades, com $50 \%$ e 16,67\%, respectivamente. Em $72,56 \%$ das propriedades, o estábulo era usado como local de ordenha, $24,51 \%$ ordenhava os animais na mangueira e apenas 2,94\% possuíam sala de ordenha. A ordenha manual com bezerro ao pé foi observada em 88 propriedades $(29,14 \%)$. Outros manejos foram observados em menor frequência, com $4,9 \%$ para ordenha manual sem bezerro e ordenha semifechada com bezerro. Apenas $3,9 \%$ das propriedades ordenhavam pelo sistema semifechado sem bezerro.

As estações do ano na região foram bem definidas durante o período de execução do trabalho, com precipitação pluviométrica média mensal de $210 \mathrm{~mm}$ na primavera, $240 \mathrm{~mm}$ no verão, $120 \mathrm{~mm}$ no outono e $60 \mathrm{~mm}$ no inverno. A temperatura variou de $8{ }^{\circ} \mathrm{C}$ à $32^{\circ} \mathrm{C}$ (mínima e máxima) na primavera, $14{ }^{\circ} \mathrm{C}$ à $35^{\circ} \mathrm{C}$ no verão, $3{ }^{\circ} \mathrm{C}$ à $31^{\circ} \mathrm{C}$ no outono e $2^{\circ} \mathrm{C}$ à $31^{\circ} \mathrm{C}$ no inverno (INMET, 2011). Para animais mestiços e zebuínos, a zona de conforto térmico varia de 5 a $31^{\circ} \mathrm{C}$ nos períodos chuvosos, e de 10 a $27^{\circ} \mathrm{C}$ nos períodos secos (PEREIRA, 2005).

O ITU (Índice de Conforto Térmico) na primavera e verão variou de 72 a 75 e ficou abaixo de 72 nos meses de outono e inverno (INMET, 2011). Esse índice determina as condições de estresse de acordo com a sensa- 
ção térmica do animal. Segundo Johnson (1987), os valores médios de ITU encontrados neste trabalho indicam que o leite foi produzido em condições ambientais amenas. Porém, para Hahn (1985), valores de ITU entre 71 e 78 são indicativos de uma condição crítica.

O estresse causado pelo calor acomete animais com diferentes níveis de produção. As temperaturas elevadas, os dias mais longos e pouco sombreamento no verão, acarretam em condições inadequadas para as vacas em lactação (MACHADO, 1998). De acordo com West (2003), em tais condições, vacas de leite possuem dificuldade para dispersar o calor corpóreo, fato que pode ter ocorrido nas propriedades onde foram realizadas as colheitas das amostras.

Segundo Santos; Fonseca (2007), a atividade das vacas diminui à medida que ultrapassa $27^{\circ} \mathrm{C}$, independentemente de idade, estágio de lactação e umidade relativa do ar. Dessa forma, vacas com elevadas temperaturas corpóreas exibem baixo consumo de matéria seca e produtividade leiteira, como visto no presente estudo.

Durante o inverno e verão todos os componentes analisados não sofreram diferença significativa, possivelmente porque as alte- rações na qualidade tenham sido diluídas ao longo da lactação, e por isso não foi encontrada diferença $(\mathrm{p}>0,05)$.

Os componentes analisados foram diferentes $(p<0,05)$ em pelo menos uma das estações (Tabela 1), com exceção da proteína.

No presente estudo, as porcentagens de proteína não variaram ao longo das estações, seguindo a mesma tendência encontrada por Botaro et al. (2008). O teor de proteína da dieta possui pouco efeito sobre a produção de proteína do leite, podendo variar em torno de 0,1 a 0,2 unidades percentuais. Esse fato ajuda a explicar que, independente da influência do regime de chuvas sobre a qualidade nutricional do pasto, pode não haver variação dos teores proteicos do leite (SANTOS; FONSECA, 2007).

Por sua vez, Barber et al. (2001), observaram menores teores de proteína no verão, atribuindo o fato ao estresse calórico. Dessa forma, há diminuição nos teores de caseína do leite, mesmo havendo maior disponibilidade de forragem. Apesar de haver um maior aporte de aminoácidos provenientes da digestão para a síntese láctea, os mesmos não são metabolizados em caseínas pela glândula mamária, sendo então excretados nas fezes.

Tabela 1 - Resultados médios $(\overline{\mathrm{x}})$ com seus respectivos desvios padrão $(\sigma)$ da porcentagem de gordura, proteína, sólidos totais (ST), contagem bacteriana total (CBT) e contagem de células somáticas (CCS) de amostras de leite da microrregião de Ivaiporã, segundo diferentes estações do ano.

\begin{tabular}{lccccc}
\hline & Outono & Inverno & Primavera & Verão & Total \\
\hline$N^{*}$ & 220 & 228 & 661 & 154 & 1263 \\
Gordura (\%) & $4,20^{\mathrm{a}} \pm 1,25$ & $3,73^{\mathrm{b}} \pm 1,32$ & $3,49^{\mathrm{c}} \pm 1,19$ & $3,78^{\mathrm{b}} \pm 1,01$ & $3,69 \pm 1,23$ \\
Proteína (\%) & $3,39 \pm 0,31$ & $3,17 \pm 0,34$ & $3,49 \pm 5,39$ & $3,93 \pm 7,96$ & $3,47 \pm 4,79$ \\
Lactose (\%) & $4,31^{\mathrm{b}} \pm 0,30$ & $4,45^{\mathrm{a}} \pm 0,44$ & $4,45^{\mathrm{a}} \pm 0,32$ & $4,49^{\mathrm{a}} \pm 0,22$ & $4,43 \pm 0,34$ \\
ST (\%) & $13,98^{\mathrm{a}} \pm 10,46$ & $12,31^{\mathrm{b}} \pm 1,39$ & $12,13^{\mathrm{b}} \pm 1,25$ & $12,47^{\mathrm{b}} \pm 1,06$ & $12,53 \pm 4,55$ \\
CBT (logCBT) & $2,83^{\mathrm{b}} \pm 1,03$ & $2,88^{\mathrm{b}} \pm 1,04$ & $3,15^{\mathrm{a}} \pm 0,93$ & $2,93^{\mathrm{b}} \pm 0,97$ & $3,02 \pm 0,98$ \\
CCS (logCCS) & $2,37^{\mathrm{a}} \pm 0,52$ & $2,30^{\mathrm{ab}} \pm 0,57$ & $2,26^{\mathrm{b}} \pm 0,63$ & $2,39^{\mathrm{a}} \pm 0,54$ & $2,30 \pm 0,59$ \\
\hline
\end{tabular}

*N: número de amostras. Médias seguidas de letras iguais na mesma linha não apresentaram diferença pelo teste de Tukey a $5 \%(\mathrm{p}>0,05)$ de probabilidade. 
Ainda em relação às proteínas, foi possível observar valores elevados de desvio padrão no verão e primavera. A grande variabilidade nas porcentagens proteicas nesses meses auxiliou a falta de diferença estatística durante todo o período analisado. Isso evidencia que as causas de variações não estão ligadas diretamente à sazonalidade, sendo que outros fatores, não ponderados nesse estudo, possuem maior influência na variação de proteína do leite.

Botaro et al. (2008) apontaram que fatores raciais e patológicos, como a ocorrência de mastite, também influenciam os teores de proteína do leite, tanto para amostras individuais como para as de tanques. Contudo, o efeito direto de tais fatores sobre os teores proteicos ainda não estão completamente elucidados.

A porcentagem de gordura é um dos componentes mais variáveis. Além da sazonalidade, outros fatores a influenciam, como a raça, alimentação e o estágio de lactação (ORDOÑEZ, 2005). Ponderar todas essas variáveis em estudos a campo é difícil, e por isso há divergência entre diferentes pesquisas.

Nesse trabalho a porcentagem de gordura foi maior $(\mathrm{p}<0,05)$ no outono e menor $(\mathrm{p}<0,05)$ na primavera. Os lipídeos do leite estão diretamente relacionados às porcentagens molares de ácido acético e butírico do rúmen, uma vez que são precursores primários para a síntese de gordura (WALSTRA et al., 2006).

Considerando apenas o manejo alimentar, vacas que recebem alimentação contendo alta quantidade de fibra e baixa proporção de concentrado, diminuem a taxa de propionato no rúmen e o balanço energético líquido, aumentando a secreção de gordura (WALSTRA et al., 2006).

Por outro lado, Paiva (2010) afirma que a concentração dos teores de gordura tem como principal causa o efeito sazonal da diluição e, de menor importância os fatores nutricionais.

Dessa forma também é possível inferir que o aumento das porcentagens de gordura no outono, seria em função da estação ser caracterizada como um período de rebrota das pastagens e menor oferta alimentar, com maiores chances de ocorrer restrição. Com isso, pode haver diminuição da produção total de leite, causando um efeito de concentração dos seus componentes, o que também explicaria o aumento dos níveis de sólidos totais observados no presente estudo (OLIVEIRA; TIMM, 2006).

Porém, ao analisarmos o alto valor do desvio padrão de sólidos totais no outono, podemos sugerir que a restrição alimentar não foi uniforme nas propriedades amostradas. A prática correta da suplementação não é frequente no Paraná, uma vez que apenas 33\% dos produtores recebem orientações técnicas sobre suplementação alimentar (IPARDES, 2009). Isso pode ter contribuído para a heterogeneidade dos valores médios de sólidos totais no leite. O questionário aplicado não abordava questões sobre alimentação, sendo impossível relacionar de maneira direta como o manejo alimentar influencia os valores de sólidos.

Ao observarmos a menor média para porcentagem de lactose no outono, o efeito de concentração possui ainda mais chances de ser o principal motivo do aumento da gordura e sólidos totais nessa época.

A lactose atua no equilíbrio osmótico na passagem dos componentes do sangue para o leite, sendo um componente fundamental juntamente com o sódio, o potássio e o cloro. Quanto menor a porcentagem de lactose no leite, menor o volume produzido pelo animal, uma vez que, pelo princípio da osmose, a água tende a acompanhar a maior concentração desse carboidrato (LUCEY; HORNE, 2009).

Ainda no outono, também podemos associar a lactose aos maiores porcentuais de CCS. Inflamações diminuem a força de junção das células epiteliais da glândula mamária, promovendo menor síntese desse açúcar.

A lactose, no entanto, sofre outras influências. De acordo com González (2001), 
o declínio da lactose no leite sofre mais influência pela diminuição da glicose sérica, esta que é causada por baixa condição nutricional do animal.

A CBT foi maior $(\mathrm{p}<0,05)$ na primavera em comparação às outras estações. $\mathrm{O}$ aumento da pluviosidade e da temperatura contribui para maior proliferação bacteriana no leite ordenhado. Seguindo essa mesma tendência, podemos observar o efeito da sazonalidade sobre os índices de CBT nos estudos de Roma Júnior et al. (2009) e Paiva (2010), os quais também encontraram maiores contagens nos meses chuvosos.

Porém, a pluviosidade não é o único fator que influencia a qualidade microbiológica do leite. Podemos observar o fato nesse estudo, uma vez que no verão, período de maior pluviosidade e amplitude térmica, as contagens de CBT não diferiram $(p>0,05)$ quando comparadas ao inverno e ao outono.

Matsubara et al. (2011) concluíram que a superfície mal higienizada de tetos e utensílios de ordenha, os três primeiros jatos e a água residual de latões são os principais pontos de contaminação no fluxograma de produção. A influência desses fatores pode ter causado um efeito confundidor na análise da qualidade do leite durante as estações, uma vez que as propriedades amostrais não tinham uniformidade em relação ao manejo e à higiene de ordenha.

Na primavera foram observados os menores porcentuais de gordura, com média de $3,49 \%$. Essa estação é precedida pela época da seca, sendo possível que os pastos ainda estivessem em recuperação, havendo menor ingestão de matéria seca, fundamental para a fração lipídica do leite.

Independente das causas das variações nos componentes lácteos analisados é importante salientar que não houve uniformidade na qualidade microbiológica e físicoquímica ao longo do ano. Isso pode gerar perdas para produtores e laticínios. A pior época para o aproveitamento industrial do leite foi na primavera, com menores porcentagens de sólidos, lipídeos e maiores contagens bacterianas. O ideal é que a influência do manejo e da alimentação prevaleçam sobre a influência sazonal, minimizando perdas decorrentes à oscilações nos componentes lácteos.

Bacarji et al. (2007) demonstraram como a instabilidade no recebimento da matériaprima torna ociosa a capacidade de produção nos laticínios em determinados períodos do ano, principalmente na época de seca.

Assim, fica evidente que a influência da época do ano sobre o pagamento por qualidade deve ser considerada. Indústrias que bonificam apenas o volume podem ter o rendimento dos produtos industrializados comprometidos e como consequência, menor margem de lucro (TEIXEIRA et al., 2003).

\section{CONCLUSÕES}

A sazonalidade tem influência sobre as características microbiológicas e físicoquímicas do leite na região de Ivaiporã (PR). Dessa forma, melhorias no manejo alimentar e de ordenha devem ser consideradas a fim de atenuar a influência da sazonalidade na qualidade do leite da região, minimizando perdas decorrentes às oscilações nos componentes lácteos.

Deságios no pagamento por qualidade em decorrência de altas contagens bacterianas e de células somáticas podem ser prevenidos pelos produtores de Ivaiporã através da intensificação da higiene de ordenha durante meses quentes e chuvosos, como primavera e verão, bem como os cuidados com a sanidade da glândula mamária.

Os prejuízos provenientes da variação no teor de sólidos do leite podem ser atenuados pela uniformização da suplementação alimentar durante todo o ano, sempre pautados por orientações técnicas.

Os resultados também permitem concluir que as indústrias laticinistas da região de Ivaiporã podem concentrar a produção de 
derivados com maior valor agregado no período do outono, otimizando e racionalizando o beneficiamento de produtos lácteos, uma vez que nessa época as porcentagens de gordura e sólidos foram maiores, resultando em maior rendimento de queijos e iogurtes.

\section{REFERÊNCIAS}

ACARJI, A. G; HALL, R. J.; ZANON, H. Os impactos da sazonalidade da produção de leite numa indústria de laticínio no Estado de Mato Grosso do Sul.In: SIMPÓSIO DE EXCELÊNCIA EM GESTÃO E TECNOLOGIA, 4., 2007, Resende. Anais... Resende: Associação Educacional Dom Bosco, 2007. p. 1-15.

BARBER, D. G. et al. An Approach to identifying factors affecting milk protein concentration in dairy cattle. Farm to Folk 2001. Australian Journal of Dairy Technology, v. 56, n. 2, p. 155, 2001.

BATTAGLINI, A. P. P. et al. Caracterização físico-química e microbiológica do leite bovino instável não ácido em função das estações do ano. Revista Brasileira de Medicina Veterinária, v. 35, n. 1, p. 26-32, jan/mar 2013a.

BATTAGLINI, A. P. P. et al. Difusão de Boas Práticas e Caracterização de Propriedades Leiteiras. Archivos de Zootecnia, v. 62, n. 237, p. 151-154, mar 2013b.

BAZOTTI, A. et al. Caracterização socioeconômica e técnica da atividade leiteira do Paraná. Revista Paranaense de Desenvolvimento, n. 123, p. 213-234, jul/dez 2012.

BOTARO, B. G. et al. Effect of betalactoglobulin polymorphism and seasonality on bovine milk composition. Journal of Dairy Research, v. 75, n. 2, p. 176-181, jan. 2008.
FERNANDES, R. F. et al. Influência da sazonalidade em parâmetros físico-químicos do leite cru recebido por um laticínio no norte de Minas Gerais. Revista Instituto Laticínios Cândido Tostes, v. 68, n. 393, p. 36-41, 2013.

GONZÁLEZ,D; HILARIO, F. Composição bioquímica do leite e hormônios da lactação. In: GONZÁLEZ, F. H. D.; DÜRR, J. W.; FONTANELLI, R. S. Uso do leite para monitorar a nutrição e o metabolismo de vacas leiteiras. UFRGS: Porto Alegre, 2001. p. 5-10.

HAHN, G. L. Compensatory performance in livestock: influence on environmental criteria. In: YOUSEF, M.K. Stress Physiology in Livestock, Boca Raton: CRC Press 1985. p. 52-145.

INSTITUTO BRASILEIRO DE GEOGRAFIA E ESTATÍSTICA (IBGE). Sistema IBGE de recuperação automática (SIDRA): banco de dados agregados. Pesquisa Trimestral do leite. Rio de Janeiro, 2013. Disponível em: $<$ http http://www.sidra.ibge.gov.br/>. Acesso em: 08 nov. 2013.

I N S T I T U T O N A C I O N A L D E METEOROLOGIA (INMET). Ministério da Agricultura Pecuária e Abastecimento, 2011. Disponível em: <http://www.inmet.gov.br>. Acesso em: 08 nov. 2013.

INTERNATIONAL DAIRY FEDERATION (IDF). Standard 141C:2000 Whole milk determination of milk fat, protein and lactose content. Guidance on the operation of midinfrared instruments. Brussels: FIL/IDF, 2000.

INTERNATIONAL DAIRY FEDERATION (IDF). Standard 196C:2004 Milk Quantitative determination of bacteriological quality. Guidance for establishing and verifying a conversion relationship between 
routine method results and anchor method results. Brussels: FIL/IDF, 2004.

INSTITUTO PARANAENSE DE DESENVOLVIMENTO ECONÔMICO E SOCIAL (IPARDES). Caracterização Socioeconômica da Atividade Leiteira no Paraná: sumário executivo. Curitiba: IPARDES, 2009. 29p.

JOHNSON, H. D. Bioclimate effects on growth, reproduction and milk production. In: JOHNSON H.D. (Ed.) Bioclimatology and the Adaption of Livestock. Amsterdam: Elsevier, 1987. p. 35-57.

LUCEY, J. A.; HORNE, D. S. Milk Salts: Technological Significance. In: FOX, P. F; McSWEENEY, P. L. H. Advanced Dairy Chemistry: Lactose, Water, Salts and Minor Constituents. 3.ed. New York: Springer, 2009. p. 351-389.

MACHADO, P. F. Efeitos da alta temperatura sobre a produção, reprodução e sanidade de bovinos leiteiros. In: SILVA, I. J. O. Ambiência na produção de leite em clima quente. Piracicaba: FEALQ, 1998. p. 179-188.

MATSUBARA, M. T. et al. Boas práticas de ordenha para redução da contaminação microbiológica do leite no agreste pernambucano. Semina: Ciências Agrárias, v. 32, n. 1, p. 277-286, 2011.

OLIVEIRA, D. S; TIMM, C. D. Composição do leite com instabilidade da caseína. Ciência e Tecnologia de Alimentos, v. 26, n. 2, p. 259-263, 2006.

ORDOÑEZ, J. A. Tecnologia de alimentos: componentes dos alimentos e processos. Porto Alegre: Artmed, 2005. v. 1. 294 p.

PAIVA, C. A. V. Efeitos da Produção e da
Sazonalidade Sobre a Qualidade do Leite Cru Refrigerado Processado em uma Indústria de Minas Gerais. 2010. 72 p. Dissertação (Mestrado em Ciência Animal) Universidade Federal de Minas Gerais, Belo Horizonte, 2010.

PEREIRA, C. C. J. Fundamentos da bioclimatologia aplicados à produção animal. Belo Horizonte: FEPMVZ, 2005. 195 p.

ROMA JÚNIOR, L. C. et al. Sazonalidade do teor de proteína e outros componentes do leite e sua relação com programa de pagamento por qualidade. Arquivo Brasileiro de Medicina Veterinária e Zootecnia, v. 61, n. 6, p. 14111418, 2009.

SANTOS, M. V.; FONSECA, L. F. L. Estratégias para controle de mastite e melhoria da qualidade do leite. São Paulo: Manole, 2007. 314p.

SOUZA, R. et al. Produção e qualidade do leite de vacas da raça Holandesa em função da estação do ano e ordem de parto. Revista Brasileira de Saúde e Produção Animal, v. 11, n. 2, p. 484-495, 2010.

TEIXEIRA, N. M; FREITAS, A. F; BARRA, R. B. Influência de fatores de meio ambiente na variação mensal da composição e contagem de células somáticas do leite em rebanhos no Estado de Minas Gerais. Arquivo Brasileiro de Medicina Veterinária e Zootecnia, v. 55, n. 4, p. 491-499, 2003.

WALSTRA, P. et al. Dairy Science and Technology. 2. ed. Boca Raton: CRC Press, 2006. 808 p.

WEST, J. W. Effects of heat-stress on production in dairy cattle. Journal of Dairy Science, v. 86, n. 6, p. 2131-2144, 2003. 